\title{
Pearls
}

\section{Pearls: Never Write a Research Grant Alone}

\author{
Michelle Ghert MD, FRCSC
}

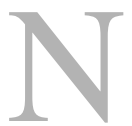

o matter how compelling a research question may be, answering it often depends on the acquisition of research funding. With funding-success rates declining steadily [1], ensuring sufficient resources to sustain a research program has become an uncertain proposition for many scientists and clinicianinvestigators.

Grants get funded (or not) for many reasons, but I think most grants go to research teams that funding agencies believe contain a high degree of

\section{A note from the Editor-in-Chief:}

We are pleased to present the next installment of "Pearls", a column in Clinical Orthopaedics and Related Research ${ }^{\circledR}$. In this column, distinguished surgeons, scientists, or scholars share surgical or professional tips they use to help surmount important or interesting problems. We welcome reader feedback on all of our columns and articles; please send your comments to eic@clinorthop.org.

The author certifies that neither she, nor any members of her immediate family, have any commercial associations (such as consultancies, stock ownership, equity interest, patent/licensing arrangements, etc) that might pose a conflict of interest in connection with the submitted article. All ICMJE Conflict of Interest Forms for authors and Clinical Orthopaedics and Related Research ${ }^{\mathbb{R}}$ editors and board members are on file with the publication and can be viewed on request. expertise and ability. Therefore, when writing a research grant, it is critical to define who will be on the team. All research grants are submitted by a Principal Investigator (PI), but there may be many co-PIs and collaborators involved. These team members can be fellow researchers, methodologists, clinical experts, statisticians, and sometimes even patient representatives. The more-developed the research team, the better the odds of success.

Put in this context, it is critical for PIs not to write their grants alone. Grants written by one person read like they were written by one person, and not by the team they represent. One person (often the PI) can formulate a research idea, but the plan should derive from discussions with colleagues and collaborators. Indeed, a research grant proposal should include the voices of all of the team members. That said, it can be challenging not

The opinions expressed are those of the writers, and do not reflect the opinion or policy of $C O R R^{\circledR}$ or The Association of Bone and Joint Surgeons ${ }^{\circledR}$.

M. Ghert MD, FRCSC ( $\square)$

McMaster University and Hamilton

Health Sciences, 711 Concession Street,

Hamilton, ON L8V 1C3, Canada

e-mail: ghert@hhsc.ca only to make sure that all the appropriate voices are heard, but that the final grant maintains a cohesive and flowing narrative. To achieve this balance, I suggest starting with an outline, and inviting the whole team to comment on it early in the grant-writing process. At this stage, team members can also decide which section of the grant most suits their expertise. For example, the statistician can write the sample-size calculation and statistical plan, while the team's methodologists can focus on the sections falling within his or her purview. For clinical research, not surprisingly, the clinician-scientists (often including the PI) typically tackle the background and rationale sections of the grant. The approach to this stage seems logical to the point of being obvious. However, there are hidden challenges related to individual schedules, expectations, and habits that can impede the progress of the initial grant-writing steps. One way to handle these potential challenges is to arrange for a half-day or full-day meeting of all investigators in which the overall theme of the grant and the individual team member assignments are clearly laid out, including the specific timelines to be met. An inperson meeting allows the investigators to become familiar with one 


\section{Pearls}

another and to develop an intellectual and emotional bond related to the goals of the research.

In the opinion of the PI or some team members, the completed grant may look just fine-save it and send it. However, the more eyes that read a grant, the more comprehensive the feedback will be. All co-PIs and collaborators should be given the opportunity to provide constructive feedback on the sections that they did not write and assess them for readability and clarity, as well as the overall flow of the grant. Sometimes, the PI may go a step further and invite more senior colleagues or even some friends (or rivals) to read the grant and to communicate their impressions of the proposed grant and its presentation, as well as their view on expected reviewer critiques.
Opening up the team to potential criticism is a difficult, but critical step. Speaking personally, I have found receiving, and more importantly accepting, feedback to be the most challenging aspect of writing a research grant. Some team members may take the criticisms personally, or feel challenged in their expertise. It is the PI's responsibility to moderate the responses and critiques, ensure that the issues brought up by the reviewers are adequately addressed, and confirm that all team members are satisfied with the updates to the grant.

Once all revisions are incorporated, I recommend that the PI meticulously read the grant again, tinkering with the documents until it is deemed "ready for submission." This "tinkering stage" can become tedious, and it is difficult to know when to stop editing and press "send." If the PI included all team members in the drafting process, incorporated feedback from both inside and outside the team, went over the grant line-by-line, and is actually looking forward to having a review panel read his/her grant, then it is time to submit. This is unlikely to be the case if the PI had written the grant in isolation.

Take home point: Never write a research grant alone.

\section{Reference}

1. US Department of Health and Human Services. NIH data book. Available at: https://report.nih.gov/nihdatabook/ index.aspx. Accessed June 15, 2017. 